\title{
SURVEY DAN EVALUASI TINGKAT KERUSAKAN PERMUKAAN JALAN SUATU RUAS JALAN
}

\author{
ISMAIL \\ Dosen Tetap Yayasan Perguruan Tinggi Palembang \\ Program Studi Teknik Sipil Fakultas Teknik Sipil Universitas Palembang \\ e-mail : smail 64@yahoo.co.id
}

\begin{abstract}
Abstrak, Kerusakan pada suatu ruas jalan akan mengalami dampak yang cukup besar pada arus lalu lintas yang melewatinya. Kerusakan jalan dapat disebabkan oleh Retak halus, retak buaya, retak pinggir, retak keriting, lubang, amblas, kegemukan, pelepasan butiran,dan pengelupasan lapisan permukaan. Pada hasil penelitian di jalan Srijaya Raya sampai Batas Kota Palembang diketahui bahwa jenis kerusakan yang terdapat di ruas jalan tersebut yaitu retak halus, retak buaya, retak pinggir, retak keriting, amblas, kegemukan dan yang paling dominan pada ruas jalan tersebut yaitu lubang dan pelepasan atau pengelupasan lapisan permukaan. Tingkat kerusakan pada ruas jalan tersebut di tentukan dengan 2 metode, yaitu metode Road Condition Index (RCI) dan dengan metode Pavement Condition Index (PCI). Sehingga dari kedua cara ini dapat disimpulkan bahwa jalan tersebut dalam keadaan sangat jelek dan harus dilakukan perbaikan jalan. Anggaran yang diperkirakan untuk perbaikan pada jalan tersebut yaitu Rp. $70,766,898,000.00$.
\end{abstract}

Kata Kunci : Perbaikan Jalan, Road Condition Index. Pavement Condition Index.

Abstract, Damage to a road segment will have a considerable impact on traffic flow through it. Road damage can be caused by smooth cracks, crocodile cracks, fractured edges, curly cracks, holes, collapsed, obesity, granular discharge, and surface layer peeling. In the result of research on Srijaya Raya road to Batas Kota Palembang, it is known that the type of damages in the road segment are fine crack, crocodile crack, fracture, curly crack, ambulance, obesity and the most dominant in the road segment is hole and discharge or flaking surface coating. The level of damage to the road segment is determined by 2 methods, the Road Condition Index (RCI) method and the Pavement Condition Index method (PCI). So from both ways it can be concluded that the road is in very bad condition and must be done road repair. The estimated budget for repairs on the road is Rp. 70,766,898,000.00.

Keywords: Road Repair, Road Condition Index. Pavement Condition Index.

\section{PENDAHULUAN}

Jalan sebagai bagian sistem transportasi nasional mempunyai peranan penting terutama dalam mendukung bidang ekonomi, sosial, dan budaya serta lingkungan dan dikembangkan melalui pendekatan pengembangan wilayah agar tercapai keseimbangan dan pemerataan pembangunan untuk daerah, membentuk dan memperkukuh kesatuan nasional untuk memantapkan pertahanan dan keamanan nasional, serta membentuk struktur ruang dalam rangka mewujudkan sasaran pembangunan nasional.

Suatu ruas jalan apabila terjadi kerusakan karena prasarana jalan yang terbebani oleh volume lalu lintas yang tinggi dan berulangulang, akan mengalami dampak yang cukup besar pada arus lalu lintas. Kerusakan jalan dapat dianalisis untuk mengetahui penyebab terjadinya kerusakan. Analisis tentang kerusakan jalan meliputi berbagai faktor yaitu disebabkan karena perencanaan perkerasan, perencanaan campuran, pemilihan bahan, 
proses/mutu pelaksanaan, kondisi lingkungan, lalu lintas atau gabungan dari faktor-faktor tersebut.

Adapun perumusan masalah pada penelitian adalah apa saja jenis dan tingkat kerusakan yang terjadi di Simpang Jalan Srijaya hingga batas Kota Palembang? Bagaimana perbaikan dan pemeliharaan yang harus dilakukan. Adapun tujuan penelitian yaitu mengetahui tingkat kerusakan apa saja yang terjadi dari persimpangan Jalan Srijaya Raya hingga Batas Kota Palembang dan perbaikan atau pemeliharaan apa saja yang harus dilakukan dari tingkat kerusakan yang ada. Manfaat dari penelitian ini yaitu dapat dijadikan sebagai referensi dalam menentukan jenis dan tingkat kerusakan. Dapat dijadikan bahan rujukan dalam menentukan nilai kondisi perkerasan jalan.

\section{TINJAUAN PUSTAKA 2.1 Jalan}

Menurut Undang-undang No. 13 tahun 1980 tentang jalan, jalan merupakan suatu prasarana perhubungan darat dalam bentuk apapun yang meliputi segala bagian jalan termasuk bangunan pelengkap dan perlengkapannya yang diperuntukkan bagi lalulintas. Bangunan pelengkap jalan adalah bangunan yang tidak dapat dipisahkan dari jalan seperti jembatan, lintas atas (over pass), lintas bawah (under pass) dan lainlain. Sedangkan perlengkapan jalan antara lain rambu-rambu dan marka jalan, pagar pengaman lalu lintas, pagar damija dan sebagainya.

\subsection{Jenis-Jenis Kerusakan Pada Jalan 2.2.1 Retak (Cracking)}

a) Retak Halus (Hair cracking)

Yang dimaksud retak halus adalah retak yang terjadi mempunyai celah $\leq \mathrm{mm}$. sifat penyebarannya dapat setempat atau luas pada permukaan jalan.

\section{b) Retak Kulit Buaya (alligator crack)}

Istilah lain adalah chickenwire cracks, alligator cracks, polygonal cracks, dan crazing. Lebar celah retak $\geq$ $3 \mathrm{~mm}$ dan saling berangkai membentuk serangkaian kotak-kotak kecil yang menyerupai kulit buaya atau kawat untuk kandang ayam.

\section{c) Retak Pinggir (Edge Crack)}

Retak ini disebut juga dengan retak garis (Lane Crack) dimana terjadi pada sisi tepi perkerasan/dekat bahu dan berbentuk retak memanjang (Longitudinal Cracks) dengan atau tanpa cabang yang mengarah ke bahu. Retak ini dapat terdiri atas beberapa celah yang saling sejajar.

\section{d) Retak Refleksi (Reflection Crack)}

Kerusakan ini terjadi pada lapisan tambahan (overlay), dapat berbentuk memanjang (longitudinal cracks), diagonal (diagonal cracks) yang menggambarkan pola retakan perkerasan dibawahnya. Retak ini dapat terjadi bila retak pada perkerasan lama tidak diperbaiki secara benar sebelum pekerjaan pelapisan ulang (overlay) dilakukan.

\section{e) Retak Susut (Shrinkage Crack)}

Retak yang terjadi tersebut saling bersambungan membentuk kotak besar dengan sudut tajam atau dapat dikatakan suatu interconnected cracks yang membentuk suatu seri blocks cracks. Umumnya penyebaran retak ini menyeluruh pada perkerasan jalan.

\section{f) Retak Selip (Slippage Crack)}

Kerusakan ini sering disebut dengan parabolic cracks, shear cracks, atau crescent shaped cracks. Bentuk rentang lengkung menyerupai bulan sabit atau berbentuk seperti jejak mobil disertai dengan beberapa retak. Kadang-kadang terjadi bersama dengan terbentuknya sungkur (shoving).

\subsubsection{Distorsi (Distortion)}

\section{a) Alur (ruts)}

Terjadi pada lintasan roda sejajar dengan as jalan, dapat merupakan tempat menggenanya air hujan yang jatuh diatas permukaan jalan, mengurangi tingkat kenyamanan dan akhirnya timbul retak-retak. 
b) Keriting (Corrugation)

Kemungkinan penyebab :

1. Rendahnya stabilitas campuran yang dapat berasal dari terlalu tingginya kadar aspal.

2. Banyak menggunakan agregat halus, agregat bulat dan licin

3. Aspal yang dipakai mempunyai penetrasi yang tinggi

4. Lalu lintas dibuka sebelum perkerasan mantap

\section{c) Sungkur (Shoving)}

Deformasi plastis yang terjadi setempat di tempat kendaraan sering berhenti, kelandaian curam, dan tikungan tajam. Kerusakan dapat terjadi dengan atau tanpa retak. Penyebab kerusakan sama dengan keriting. Perbaikan kerusakan sama dengan keriting.

\section{d) Amblas (Grade Depresion)}

Terjadi ditempat/tertentu

dengan atau tanpa retak, terdeteksi dengan adanya air yang tergenang. Amblas disebabkan oleh beban kendaraan yang melebihi apa yang direncanakan, pelaksanaan yang kurang baik, atau penurunan bagian perkerasan dikarenakan tanah dasar menglami settlement.

\section{e) Jembul (Upheaval)}

Jenis kerusakan jembul terjadi setempat dengan atau tanpa retak. Hal ini terjadi akibat adanya pengembangan tanah dasr ekspansip. Perbaikan dilakukan dengan membongkar bagian yang rusak dan melapisinya kembali.

\subsubsection{Cacat}

\section{Permukaan}

\section{(Disintegration)}

a) Lubang (Potholes)

Kerusakan jalan berbentuk lubang (potholes) memiliki ukuran yang bervariasi dari kecil sampai besar. lubang-lubang ini menampung dan meresapkan air sampai ke dalam lapis permukaan yang dapat menyebabkan semakin parahnya kerusakan jalan. b) Pelepasan butir (Raveling)

Dapat terjadi secara meluas dan mempunyai efek serta disebabkan oleh hal yang sama dengan lubang. Dapat diperbaiki dengan memberikan lapisan tambahan diatas lapisan yang mengalami pelepasan butir setelah lapisan tersebut dibersihkan dan dikeringkan.

\section{c) Pengelupasan Lapisan Permukaan} (Stripping)

Disebabkan oleh kurangnya ikatan antara lapisan permukaan dan lapis bawahnya, atau terlalu tipisnya lapis permukaan. Dapat diperbaiki dengan cara digaruk, diratakan, dan dipadatkan. Setelah itu dilapisi dengan buras.

\subsubsection{Pengausan (Polished Aggregate)}

Pengausan terjadi karena agregat berasak dari material yang tidak tahan aus terhadap roda kendaraan / agregat yang digunakan berbentuk bulat dan licin. Dapat diatasi dengan latasir, buras, latasbum.

\subsubsection{Kegemukan (Bleeding/Flushing)}

Pada temperature tinggi, aspal menjadi lunak, dan akan terjadi jejak roda, dapat disebabkan pemakaian kadar aspal yang tinggi pada campuran aspal, pemakaian terlalu banyak aspal pada pengerjaan prime coat/teak coat. Dapat diatasi dengan menaburkan agregat panas dan kemudian dipadatkan atau lapis aspal diangkat dan diberi penutup.

\subsubsection{Penurunan Pada Bekas Penanaman Utilitas (Utility Cut Depretion)}

Hal ini terjadi karena pemadatan yang tidak memenuhi syarat. Dapat diperbaiki dengan dibongkar kembali dan diganti dengan lapis yang sesuai.

\subsection{IRMS (Integrated Road Management System)}

Integrated Road Management System atau disingkat IRMS adalah suatu sistem perangkat lunak terpadu yang digunakan untuk "membantu" perencana jalan dalam menghimpun data dan merencanakan program pemeliharaan jalan Nasional dan Provinsi. Data-data utama yang dipakai dalam pemograman IRMS, adalah sebagai berikut : 


\subsubsection{Data Titik Referensi (STR/DRP)}

Survai data titik referensi disingkat STR (Data Reference Point Survai, DRP) dimaksudkan untuk menentukan titik-titik referensi pada satu ruas jalan yang akan digunakan sebagai pedoman dalam pelaksanaan survai jalan lainnya.

\subsubsection{Data Inventaris Jalan (RNI)}

Survai Invetaris Jalan disingkat SIJ

(Road Network Inventory, RNI) dimaksudkan untuk menginventarisasi atau mencatat keadaaan jalan saat ini dan juga saat yang lampau sebagai data sejarah perkembangan jalan tersebut dalam bentuk table/tekstur.

\subsubsection{Data Kondisi Jalan (RCS)}

Survei ini adalah bagian dari survey rutin untuk keseluruhan jaringan jalan dan hendaknya dilakukan pada musim panas.

\subsubsection{International Roughness Index (IRI)}

International Roughness Index (IRI) atau ketidakrataan permukaan jalan dikembangkan oleh Bank Dunia pada tahun 1980an. IRI digunakan untuk menggambarkan suatu profil memanjang dari suatu jalan dan digunakan sebagai standar ketidakrataan permukaan jalan.

\subsubsection{Data Perhitungan Lalu lintas Rutin (LHR)}

Survai perhitungan lalu lintas adalah kegiatan pokok dan sangat penting dilakukan untuk mendapatkan data volume lalu lintas untuk berbagai keperluan teknik lalu lintas maupun perencanaan transportasi.

\subsubsection{Road Condition Index (RCI)}

Road Condition Index (RCI), disebut juga indeks kondisi jalan, merupakan kinerja fungsional perkerasan yang dikembangkan oleh American Association of Stat Higway Officials (AASHO) pada tahun 1960an.

\begin{tabular}{l} 
Tabel 1. Kondisi Permukaan Jalan \\
Secara Visual dan Nilai RCI \\
\begin{tabular}{|c|c|}
\hline RCI & $\begin{array}{c}\text { Kondisi Permukaan Jalan } \\
\text { secara Visual }\end{array}$ \\
\hline $8-10$ & Sangat rata dan teratur \\
\hline $7-8$ & Sangat baik, umumnya rata \\
\hline $6-7$ & Baik \\
\hline $5-6$ & $\begin{array}{c}\text { Cukup, sedikit sekali atau tidak } \\
\text { ada lubang tetapi permukaan } \\
\text { jalan tidak rata }\end{array}$ \\
\hline $4-5$ & $\begin{array}{c}\text { Jelek, kadang-kadang ada } \\
\text { lubang, permukaan jalan tidak } \\
\text { rata }\end{array}$ \\
\hline $3-4$ & $\begin{array}{c}\text { Rusak, bergelombang, banyak } \\
\text { lubang }\end{array}$ \\
\hline $2-3$ & $\begin{array}{c}\text { Rusak berat, banyak lubang } \\
\text { dan seluruh daerah perkerasan } \\
\text { hancur }\end{array}$ \\
\hline$\leq 2$ & $\begin{array}{c}\text { Tidak dapat dilalui kecuali } \\
\text { dengan 4WD Jeep }\end{array}$ \\
\hline Sumber : Sukirman (1999)
\end{tabular} \\
\hline
\end{tabular}

\subsection{Pavement Condition Index (PCI)}

Pavement Condition Index (PCI) adalah salah satu system penilaian kondisi perkerasan jalan berdasarkan jenis, tingkat kerusakan yang terjadi dan dapat digunakan sebagai acuan dalam usaha pemeliharaan.

\subsubsection{Density (Kadar Kerusakan)}

Density atau kadar kerusakan persentase luasan dari suatu jenis kerusakan terhadap luasan suatu unit segmen yang diukur meter persegi atau meter panjang. Nilai density suatu jenis kerusakan dibedakan juga berdasarkan tingkat kerusakannya.

Rumus mencari nilai density:

$$
\begin{aligned}
& \text { Density }=\frac{A d}{A S} \times 100 \% \\
& \text { Atau } \\
& \text { Density }=\frac{L d}{A S} \times 100 \% \text {. }
\end{aligned}
$$

Dengan :

Ad : Luas total jenis kerusakan untuk tiap tingkat kerusakan $\left(\mathrm{m}^{2}\right)$. 
Ld : Panjang total jenis kerusakan untuk tiap tingkat kerusakan (m)

As : Luas total unit segmen $\left(\mathrm{m}^{2}\right)$.

\subsubsection{Deduct Value \\ Pengurangan)}

Deduct Value adalah nilai pengurangan untuk tiap jenis kerusakan yang diperoleh dari kurva hubungan antara density dan Deduct Value. Deduct Value juga dibedakan atas tingkat kerusakan untuk tiap-tiap jenis kerusakan.

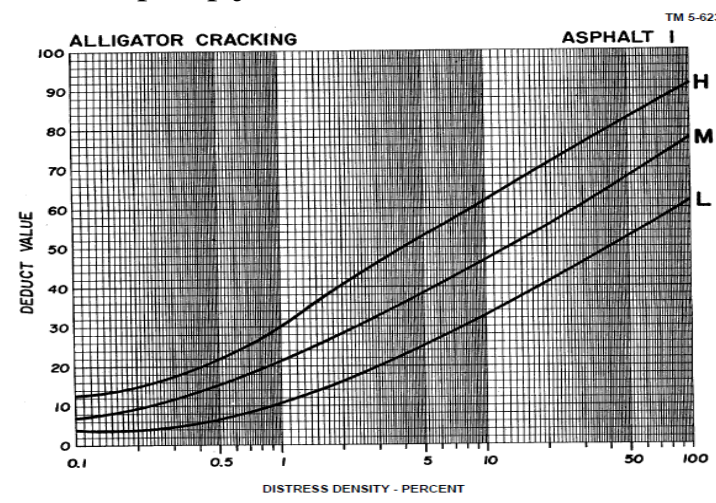

Gambar 1. Curva Deduct Value Retak Buaya

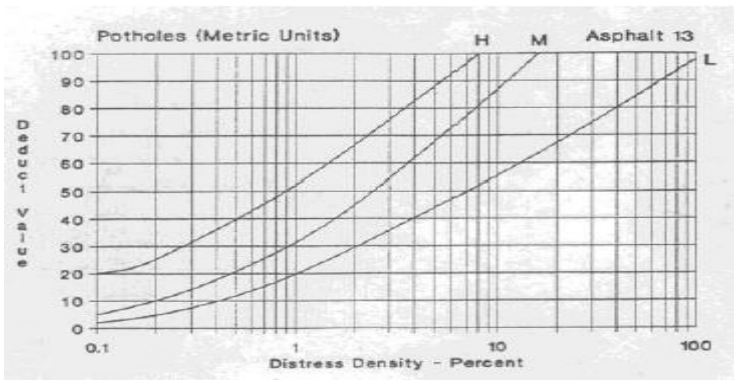

Gambar 2. Curva Deduct Value Lubang

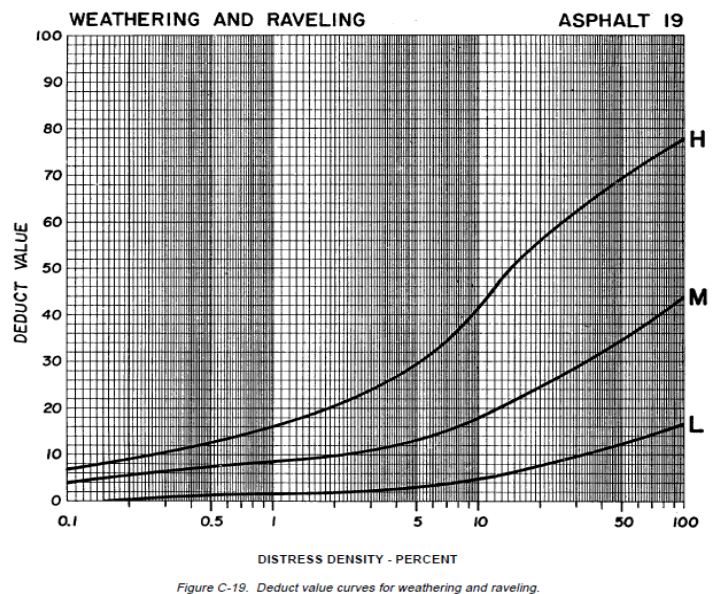

Gambar 3. Curva Deduct Value Pengelupasan Permukaan

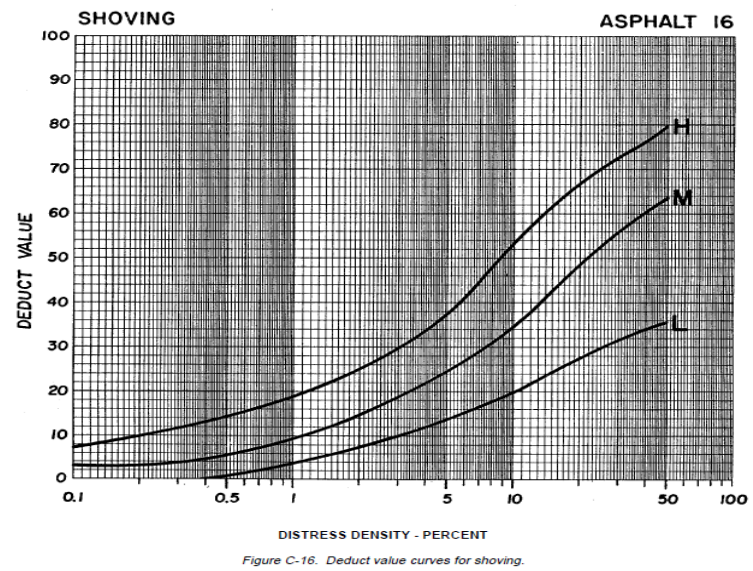

Gambar 4. Curva Deduct Value Retak Keriting

\subsubsection{Mencari Nilai q (Quality)}

Nilai q didapat dari Deduct Value yang nilainya lebih dari syarat. Syarat untuk mencari nilai q adalah deduct Value lebih besar dari 2 dengan menggunakan interasu. Nilai deduct Value diurutkan dari yang besar sampai kecil. Nilai pengurang total atau total deduct Value (TDV) adalah jumlah total dari nilai-nilai pengurang (deduct Value) pada masing-masing sampel unit. Sebelumnya dilakukan pengecekan nilai deduct Value dengan persamaan (3).

$\mathrm{Mi}=1+(9 / 98) *(100-\mathrm{HDVi})$

Dengan :

$\mathrm{Mi} \quad=$ Nilai koreksi untuk deduct Value

HDVi = Niali terbsar deduct Value dalam satu sampel unit

Jika semua nilai deduct Value lebih besar dari nilai Mi maka dilakukan pengurangan, tetapi jika semua nilai deduct Value lebih kecil dari nilai Mi maka tidak dilakukan pengurangan terhadap nilai deduct Value tersebut.

\subsubsection{Total Deduct Value (TDV)}

Total Deduct Value (TDV) adalah nilai total dari Individual Deduct Value untuk tiap jenis kerusakan dan tingkat kerusakan yang ada pada suatu unit penelitian.

\subsubsection{Corrected Deduct Value (CDV)}

Corrected Deduct Value (CDV) adalah diperoleh dari kurva hubungan antara nilai TDV dengan nilai CDV dengan pmilihan lengkung kurva sesuai dengan jumlah nilai individual deduct value yang mempunyai nilai besar dari 2 (dua). 


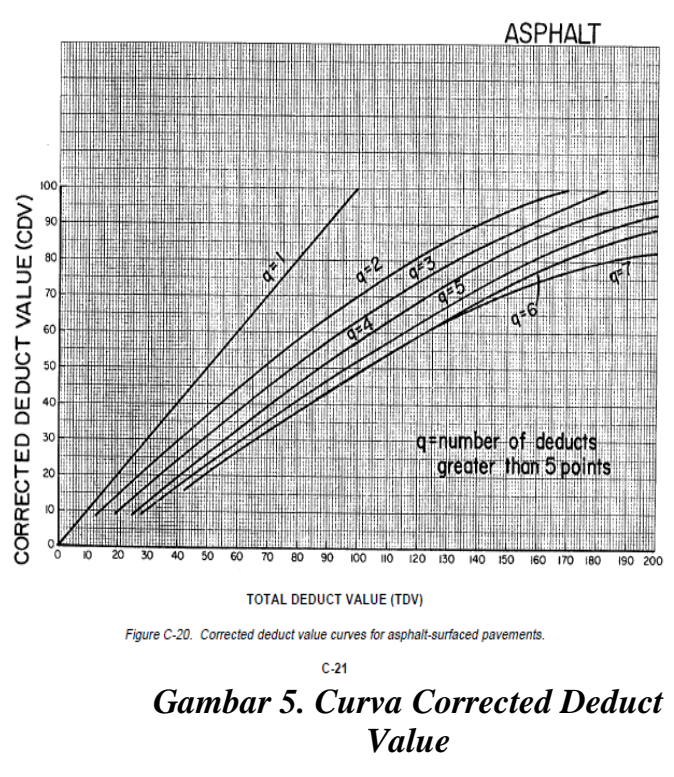

\subsubsection{Klasifikasi Kualitas Perkerasan}

Jika nilai CDV telah dikektahui, maka nilai PCI untuk tiap unit dapat diketahui dengan rumus :

$\mathrm{PCI}_{(\mathrm{S})}=100-\mathrm{CDV}$

Dengan :

$\mathrm{PCI}_{(\mathrm{S})}=$ Pavement Condition Index untuk tiap unit

CDV = Corrected Deduct Value untuk tiap unit

Untuk nilai PCI secara keseluruhan :

$$
\text { PCI }=\frac{\Sigma P C I_{(S)}}{N} \text {. }
$$

Dengan :

PCI = nilai PCI perkerasan keseluruhan

$\mathrm{PCI}_{(\mathrm{S})}=$ Pavement Condition Index untuk tiap unit.

$\mathrm{N}=$ Jumlah Unit

Nilai PCI untuk masing-masing unit penelitian dapat mengetahui kualitas lapis perkerasan unit segmen berdasarkan kondisi tertntu yaitu sempurna (excellent), sangat baik (Very Good), baik (Good), sedang (Fair), jelek (Poor), sangat jelek (Very Poor), dan gagal (Failed).

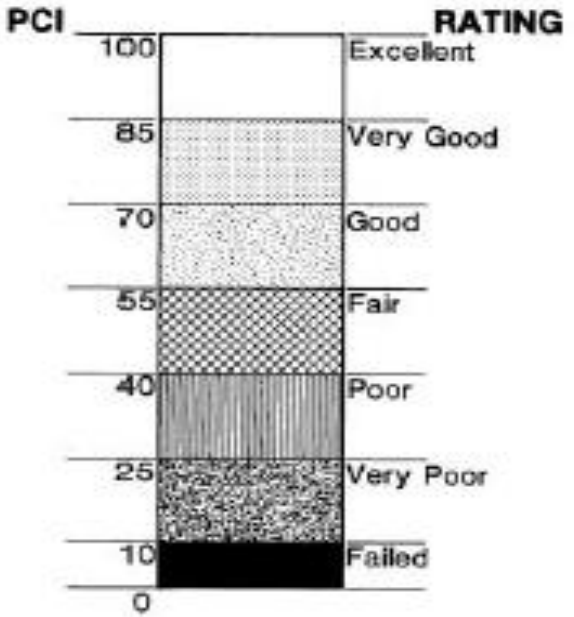

Gambar 6. Diagram Pavement Condition Index (PCI)

\section{METODE PENELITIAN \\ 3.1 Obyek Penelitian}

Obyek yang diambil pada Penelitian Tugas Akhir ini adalah Jalan Srijaya Raya.

\subsection{Lokasi Penelitian}

Lokasi Penelitian pada Tugas Akhir ini adalah dari Simpang jalan Srijaya Raya sampai Batas Kota Palembang

\subsection{Bagan Alir Penelitian}

Secara umum proses penelitian yang akan dilakukan didesain sedemikian rupa dengan mengikuti bagan alir (flowchart) seperti dipertunjukkan pada gambar 7 .

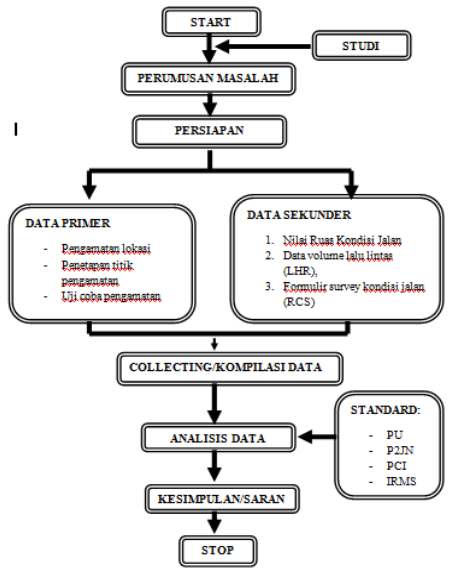

Gambar 7. Bagan Alir Penelitian 


\section{IV.HASIL DAN PEMBAHASAN}

Dari hasil survey yang dilakukan dari simpang jalan srijaya raya hingga batas Kota Palembang diketahui bahwa jenis kerusakan yang terdapat di ruas jalan tersebut yaitu retak halus, retak buaya, retak pinggir, retak keriting, amblas, kegemukan dan yang paling dominan pada ruas jalan tersebut yaitu lubang dan pelepasan atau pengelupasan lapisan permukaan.

Adapun nilai Road Condition Index (RCI) untuk permukaan jalan di jalur simpang jalan raya hingga batas Kota Palembang ini yaitu 4 dan untuk permukaan jalan di jalur batas Kota Palembang sampai simpang jalan Srijaya Raya ini yaitu 3 . Adapu nilai rata-rata Pavement Condition Index (PCI) yang didapat dari keseluruhan ruas Jalur dari simpang jalan Srijaya Raya hingga Batas Kota Palembang sepanjang 6.222 meter atau 6,22 km adalah 15 yang berarti kondisi jalan tersebut berada pada golongan atau tingkatan level Very Poor atau Serius dan harus dilakukan perbaikan jalan. Anggaran yang diperkirakan untuk perbaikan pada jalan tersebut yaitu $\mathrm{Rp}$. 70,766,898,000.00.

\section{KESIMPULAN DAN SARAN 5.1 Kesimpulan}

Adapun kesimpulan yang penulis ambil dari hasil penelitian mengenai tingkat kerusakan Jalan pada ruas Jalan Srijaya Raya sampai Batas Kota Palembang yaitu:

1. Pada jalur jalan dari simpang Jalan Srijaya Raya sampai Batas Kota Palembang jenis kerusakan yang sering ditemukan yaitu: retak halus, retak pinggir, yang paling dominan yaitu Lubang, Pengelupasan Permukaan/Butiran dan Penurunan/penambahan. Sedangkan pada jalur jalan sebaliknya yaitu dari Batas Kota Palembang hingga Simpang Jalan Srijaya Raya jenis kerusakan yang sering ditemukan pada jalur jalan ini yaitu: retak halus, retak buaya, retak pinngir, retak keriting, serta yang paling dominan yaitu lubang dan pengelupasan permukaan/butiran, kegemukan, dan yang terakhir yaitu penurunan/penambahan jalan.
2. Tingkat kerusakan pada Jalan Srijaya Raya sampai Batas Kota Palembang jika dihitung dengan Metode RCI (Road Condition Index) dan metode PCI ( Pavement Condition Index) yaitu menghasilkan bahwa jalan tersebut dikategorikan sangat buruk (Very Poor).

3. Dari hasil kedua nilai baik RCI (Road Condition Index) atau PCI (Pavement Condition Index) diketahui bahwa pada jalan dari simpang Jalan Srijaya Raya sampai Batas Kota Palembang dalam kondisi buruk sehingga perlu perbaikan dengan cara Jalan dilapisi dengan lapis pondasi aggregate kelas $\mathrm{A}$, kemudian jalan dilaburi Aspal (Buras), setelah itu dilapisi lapis resap pengikat (Prime Coat) dan Lapis perekat (Tack Coat), dan yang terakhir dengan campuran aspal panas (Hot Mix). Anggaran yang diperkirakan untuk perbaikan pada jalan tersebut yaitu Rp. 70,766,898,000.00.

\subsection{Saran}

Adapun saran pada penelitian Tugas Akhir ini adalah

1. Hasil studi yang dilakukan menunjukkan bahwa kerusakan pada Simpang Jalan Srijaya Raya sampai Batas Kota Palembang menghasilkan kategori Very Poor, sehingga rekomendasi selanjutnya yaitu perlunya kajian terhadap kerusakan dibawah permukaan perkerasan.

2. Perlu dilakukannya studi berkelanjutan dengan membandingkan antara nilai perkerasan yang telah didapat dengan International Roughness Index (IRI), karena perbaikan Jenis kerusakan terhadap jenis kendaraan yang melintasi.

3. Untuk Ruas Jalan di sepanjang jalan Srijaya Raya hingga Batas Kota Palembang perlu diberi saluran air atau selokan, walaupun ada saluran air atau selokan perlu dilakukan pembersihan agar saluran air atau selokan tidak tersumbat dan pada jalan tersebut perlu diberi bahu jalan atau perlu diberi Daerah Milik Jalan (Damija) agar masyarakat dapat berjalan dengan aman. 


\section{DAFTAR PUSTAKA}

Departemen Pekerjaan Umum, Direktorat Jenderal Bina Marga, Dokumen Penawaran, Satuan Kerja Non Vertikal Tertentu Pembangunan Jalan dan Jembatan, 2008

.......... Deduct Value Curves-Asphalt Surfaced Jointed Concrete Pavement.www.discountpdh.com (PDF)

Dwindah,Oktiara, Kerusakan dan Perkerasan Jalan,2011

Hamirhan Saodang MSCE, Ir, Konstruksi Jalan Raya, Penerbit Nova. 2004 https://balai3.wordpress.com/2011/06/07/pe ngenalan-program-irms-ver-ii/ http://perencanaankota.blogspot.com/2013/ 10/menurut-undang-undang-no.html https://www.scribd.com/doc/59838593/Ker usakan-pada-perkerasan-aspalUniversitasGunadarma https://www.academia.edu/9657722/Artikel _Pengendalian_Kerusakan_Jalan ......... Kementerian Pekerjaan Umum Bina Marga Provinsi Sumatera Selatan ......... Kementerian Pekerjaan Umum, Direktorat Jenderal Bina Marga, Penjelasan Umum Manual Survai Data IRMS. 2011

......... Perencanaan dan Pengawasan Jalan Nasional (P2JN)

Suhardi,M.Sc, Ir, Implementasi Program Keselamatan Jalan, Direktur Bina Teknik, Direktorat Jenderal Bina Marga. 2012 Yani, Ahmad, Evaluasi Jenis dan Tingkat Kerusakan Dengan Menggunakan Pavement Condition Index (PCI). 2011 www.BP2JN.com 